\title{
A unified approach
} for including non-extractable residues (NER) of chemicals and pesticides in the assessment of persistence

\author{
Andreas Schäffer ${ }^{1 *}$, Matthias Kästner ${ }^{2}$ and Stefan Trapp ${ }^{3}$
}

\begin{abstract}
All chemicals form non-extractable residues (NER) to various extents in environmental media like soil, sediment, plants and animals. NER can be quantified in environmental fate studies using isotope-labeled (such as ${ }^{14} \mathrm{C}$ or ${ }^{13} \mathrm{C}$ ) tracer compounds. Previous NER definitions have led to a mismatch of legislation and state of knowledge in research: the residues are assumed to be either irreversibly bound degradation products or at least parts of these residues can be released. In the latter assumption, soils and sediments are a long-term source of slowly released residues. We here present a conceptual experimental and modeling approach to characterize non-extractable residues and provide guidance how they should be considered in the persistence assessment of chemicals and pesticides. Three types of NER can be experimentally discriminated: sequestered and entrapped residues (type I), containing either the parent substance or xenobiotic transformation products or both and having the potential to be released, which has indeed been observed. Type II NER are residues that are covalently bound to organic matter in soils or sediments or to biological tissue in organisms and that are considered being strongly bound with very low remobilization rates like that of humic matter degradation rates. Type III NER comprises biogenic NER (bioNER) after degradation of the xenobiotic chemical and anabolic formation of natural biomolecules like amino acids and phospholipids, and other biomass compounds. We developed the microbial turnover to biomass (MTB) model to predict the formation of bioNER based on the structural properties of chemicals. Further, we proposed an extraction sequence to obtain a matrix containing only NER. Finally, we summarized experimental methods to distinguish the three NER types. Type I NER and type II NER should be considered as potentially remobilizable residues in persistence assessment but the probability of type II release is much lower than that of type I NER, i.e., type II NER in soil are "operationally spoken" irreversibly bound and can be released only in minute amounts and at very slow rates, if at all. The potential of remobilization can be evaluated by chemical, physical and biological methods. BioNER are of no environmental concern and, therefore, can be assessed as such in persistence assessment. The general concept presented is to consider the total amount of NER minus potential bioNER as the amount of xenoNER, type I + II. If a clear differentiation of type I and type II is possible, for the calculation of half-life type I NER are considered as not degraded parent substance or transformation product(s). On the contrary, type II NER may generally be considered as (at least temporarily) removed. Providing proof for type II NER is the most critical issue in NER assessment and requires additional research. If no characterization and additional information on NER are available, it is recommended to assess the total amount as potentially remobilizable. We propose our unified approach of NER characterization and evaluation to be implemented into the
\end{abstract}

\footnotetext{
*Correspondence: andreas.schaeffer@bio5.rwth-aachen.de

${ }^{1}$ Institute for Environmental Research, RWTH Aachen University, Worringerweg 1, 52074 Aachen, Germany

Full list of author information is available at the end of the article
} 
persistence and environmental hazard assessment strategies for REACH chemicals and biocides, human and veterinary pharmaceuticals, and pesticides, irrespective of the different regulatory frameworks.

\section{Introduction}

Criteria for the assessment of chemical properties and toxicological and environmental behavior of industrial chemicals in general, and particularly for biocidal products, plant protection products, and veterinary medicines are summarized in specific European legislations, [1-3] and guidelines [4-6], respectively. For the assessment of PBT properties under REACH, there are guidance documents available [7-9], which provide principles on the assessment of NERs. However, currently, there is no detailed description of the extraction techniques to differentiate NER types available. As there is no unified guidance available for the differentiation of different NER types in the general regulatory context, here, an approach is suggested based on a thorough review of the current scientific state of the art. Our paper is based on an extensive discussion paper on the interpretation of nonextractable residues in degradation assessment, which we would like to present to a wider audience [10].

Besides various degradation and transport processes, all chemicals that enter the environment form NER in solid matrices in varying amounts $[11,12]$. NER formation can be quantified in environmental fate studies using, e.g., ${ }^{14} \mathrm{C}$ or ${ }^{13} \mathrm{C}$-labeled tracer compounds. Previous NER definitions led to a mismatch of legislation and current state of knowledge in research and modeling; only parent compounds and primary metabolites are considered as NER, whereas remaining label conversion into natural bio-components was explicitly excluded [13]. The regulatory views on NER formation differ considerably with the two extremes of (i) assuming them as either degraded residues of no environmental concern in the regulation of pesticides $[14,15]$, at least if the NER are below or the mineralisation rates above certain threshold values, or (ii) as potentially bioavailable and nondegraded residues ("parent substance") in the regulation of general industrial chemicals $[7,9,16]$ if no clear indication for ultimate degradation or irreversible immobilization is available. In other words, NER in the respective matrix are valued either as 'safe sink' or as potential 'hidden hazard.'

We will argue why the extreme views of NER as degraded versus non-degraded and bioavailable residues have to be reconsidered and why it is necessary to distinguish degradation of chemicals from dissipation, which is only possible by characterizing the underlying mechanisms. A conceptual framework and an analytical toolbox for the characterization of NER formation as well as potential approaches for the assessment of the NER stability together with further research needs are provided.

\section{What is known}

Chemicals entering the environment undergo various abiotic and biotic turnover processes [17, 18], are taken up by living organisms, leach to the groundwater, and volatilize to the atmosphere, but a part of the chemical will always be immobilized as NER [19], i.e., fractions immobilized to solid matrices. Although these processes have been investigated for decades, the formation of NER in soils, sediments and biological tissue [20-22] is often considered 'black box' in environmental risk assessment of chemicals. Usually, NER were in the past only characterized with respect to the percentage of radioactivity associated with fulvic acid, humic acid and humin fractions of organic matter [11, 19, 20, 22-26] but underlying mechanisms of binding were only partially understood except that covalent binding to humic matter were qualitatively differentiated from non-covalent interactions like electrostatic interactions, hydrogen bonding, van der Waals forces, and hydrophobic interactions [25, 27-30].

\section{Definition of NER}

According to the mostly cited IUPAC definition [13], NER in soils are defined as species originating from chemicals that remain un-extracted by methods which do not significantly change the chemical nature of these residues. Non-extractable residues are considered to exclude fragments recycled through metabolic pathways leading to natural products. Later, it was stated [31]: "Bound residues represent compounds in soils, plants, or animals which persist in the matrix in the form of the parent substance or its transformation product(s) after extraction. The extraction method must not substantially change the compounds themselves or the structure of the matrix". However, both definitions cause potential for misunderstanding and misinterpretation: they focus on not altering the matrix, which cannot be excluded by many applied methods (see below), and the definition of Führ [31] is not considering the formation of biogenic NER. Harsher chemical or physical environmental processes such as soil acidification may alter the matrix and may also change the nature of the xenobiotic and its binding mechanism.

Since NER have to be quantified by radio isotope labeling $\left({ }^{14} \mathrm{C}\right)$ of a chemical at the most stable part of the molecule [32], the detection can only be related to the 
labelled atom and not to molecular speciation. Thus, the structural identity of NER remains unknown. Studies under identical experimental conditions, in which the xenobiotic is isotope labeled at different positions, lead to different results regarding mineralization, degradation half-lives and NER formation depending on the stability of the labelled molecular moiety. Only by specific spectroscopic techniques after labeling the molecule with suitable stable isotopes, e.g., ${ }^{13} \mathrm{C}$ or ${ }^{15} \mathrm{~N}$ for corresponding NMR analysis [33-36] or high-resolution MS [37-43] or ${ }^{14} \mathrm{C}$-labeling combined with LC-MS [44], structural features of NER have been elucidated, however, often at elevated concentrations of the test substances.

Recently, the state of the art regarding NER was reviewed and various types of NER were classified
[12]. It was concluded that the total amount of NER is the sum of strongly adsorbed or entrapped (type I) both may be considered as sequestered-and covalently bound residues (type II) both either derived from the parent substance or from transformation or degradation products; a third type (III) refers to biogenic NER that are derived from biotic degradation (see Fig. 1 and Table 1). This degradation results in label transformation to various biomolecules, e.g., amino acids, phospholipids, etc., which has been shown by stable isotope labeling $\left({ }^{13} \mathrm{C},{ }^{15} \mathrm{~N}\right)[37,38$, 40-43]. The three NER types are formed by competing processes [12]. Below, we present discriminating analytical methods in the proposal for an extraction scheme.

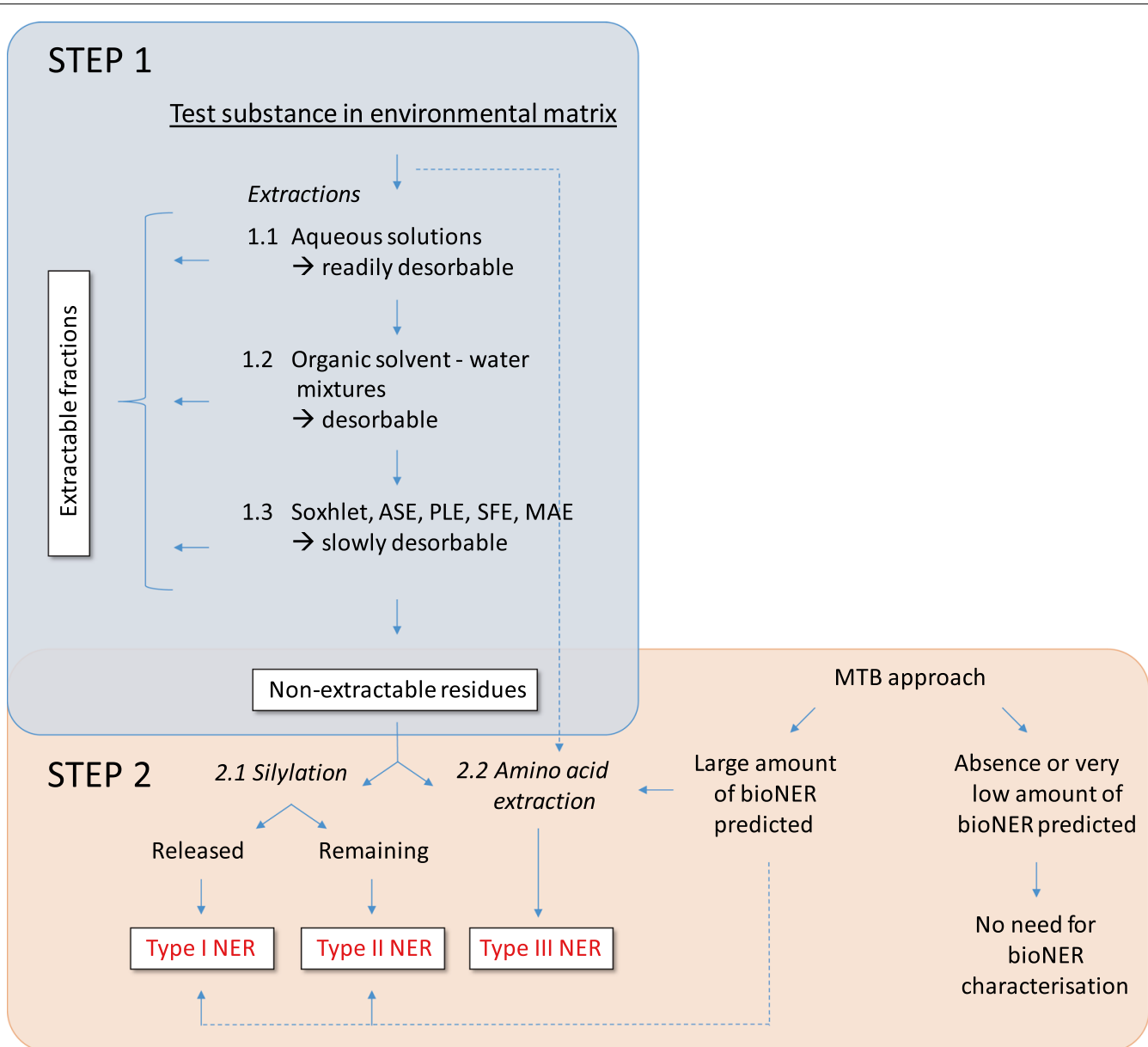

Fig. 1 Extraction scheme. Proposed scheme of extraction steps for deriving extractable fractions and investigating NER. Alkaline humic matter extraction can be used as an alternative to direct silylation of the NER containing matrix, e.g., soil. Then, each humic matter fraction (fulvic and humic acids and humin) derived by alkaline extraction has to be silylated to enable the differentiation of type I and type II NER. Amino acid extraction can be additionally performed with the whole sample prior to any extraction. The difference to the amount of bioNER can be considered as the amount of labelled biomolecules that may be extracted in the step 1 procedures 


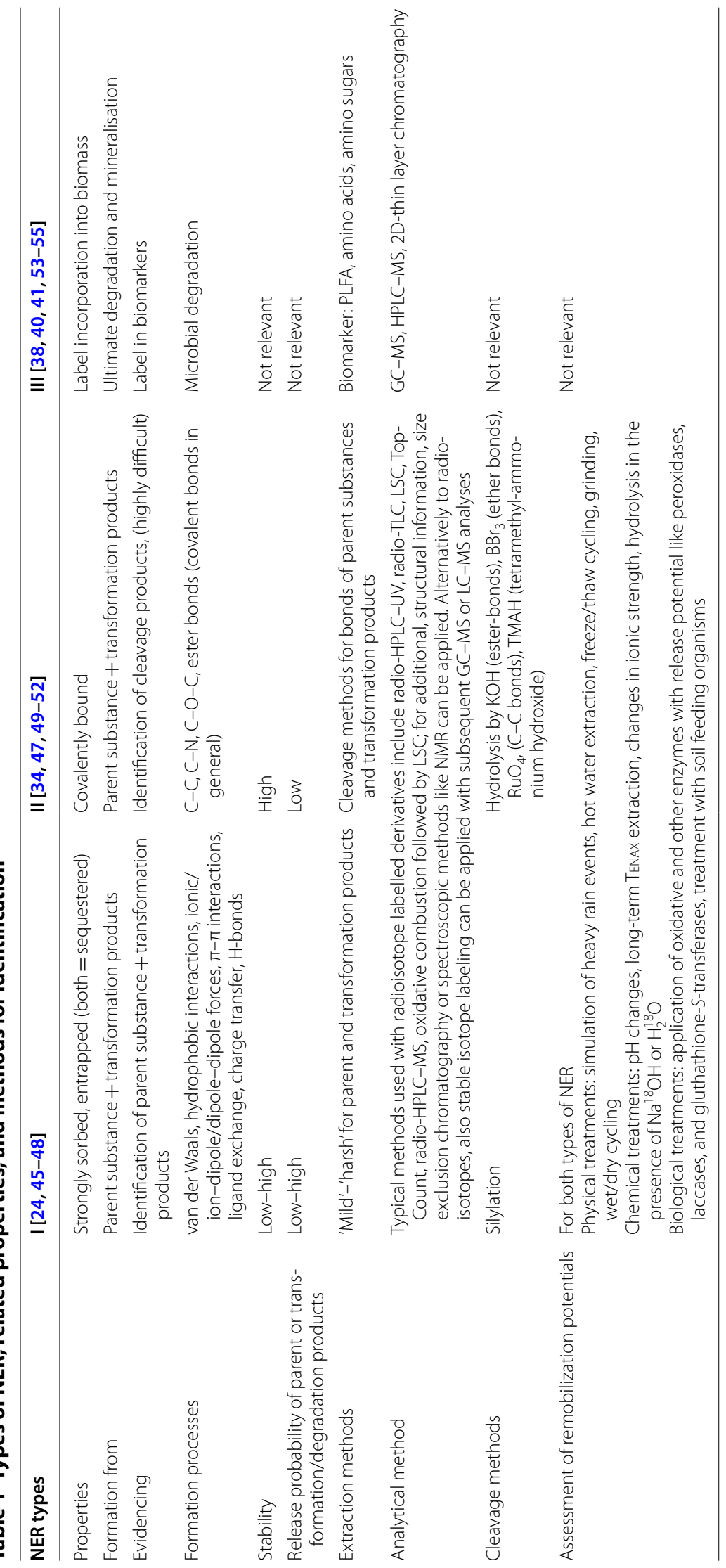




\section{Methods to extract and identify NER, limitations of the test methods and technical challenges}

The following sequence of extraction procedures is proposed to prepare an environmental matrix (soil, sediment, biological tissue) that, after removing the extractable fractions, only contains NER. If abiotically formed NER, i.e., in studies with sterilized matrix, are much lower in the control than biotically formed NER in a degradation test, this gives a clear indication on NER from degradation products or even from bioNER. If bioNER are actually formed then they can be counted as metabolized substance, in addition to $\mathrm{CO}_{2}$ and can, thus, be added to the degraded amount. If DT50 values are much lower than real DegT50 values with low amounts of resulting $\mathrm{CO}_{2}$, there is a strong indication for dissipation with formation of type I and II NER. In this case, the DegT50 value should be used in for the $\mathrm{P} / \mathrm{vP}$ assessment [9].

Table 1 presents the properties of NER and the methodologies that can be used for the identification of the three NER types.

The following stepwise approach (Fig. 1) is proposed for the assessment of extractable residues and the characterisation of NERs in environmental matrices.

Step 1 shows the sequence of three extraction steps: aqueous salt/buffer extraction (bioavailable fraction), solvent/water mixtures (potentially bioaccessible, readily desorbable fraction), and finally exhaustive extraction using Soxhlet, ASE/PLE, SFE or MAE to release the extractable fractions (total extractable, remobilisable fractions). This sequence will leave only NER remaining in the matrix, which are defined here as total NER and can be subsequently used to assess and differentiate type I, II, and type III NER (Step 2). The extraction strategy should be substance tailored, e.g., by choosing appropriate solvents (see below).

\section{Determination of extractable fractions (see Fig. 1, Step 1)}

Use of aqueous solutions to determine the amount of residues being easily desorbable Aqueous solutions will extract residues that are directly bioavailable for organisms living in the matrix, e.g., soil or sediment. A diluted $\mathrm{CaCl}_{2}$ solution, e.g., $0.01 \mathrm{M}$, is a suitable solvent for that purpose as the molarity and ionic strength resemble those of the soil pore water $[56,57]$. An initial $0.01 \mathrm{M} \mathrm{CaCl}_{2}$ extraction should be performed at every sampling interval. $\mathrm{CaCl}_{2}$ extraction has been applied to correlate simazine residue bioavailability. Simazine sorption to soil increased with aging and amounts of simazine extracted by $0.01 \mathrm{M}$ $\mathrm{CaCl}_{2}$ were clearly correlated with amounts of simazine mineralized by a simazine-mineralizing bacterium [58]. Similarly, $\mathrm{CaCl}_{2}$ extraction mimicked the bioavailable fractions of indaziflam, carbendazim and sulfadiazine in soil [59-61]. Aqueous solutions of nitrate or acetate salts can also been used for extraction [62-64].

Use of organic solvent mixtures to extract thoroughly the matrix Available residues should be sequentially extracted at ambient temperature with carefully selected aqueous:organic solvent mixtures (e.g., 50:50 or 20:80 water:acetonitrile; v:v), which at times may be modified with minute amounts $(0.1-2.5 \% \mathrm{v} / \mathrm{v})$ of formic acid, acetic acid and/or ammonia in order to enhance the solubility of the xenobiotic and/or its transformation products. Elevated temperatures are avoided for the initial extracts of the samples. Samples will be extracted for prolonged time periods (4-24 h) using physical agitation, e.g., shaking. Ultra-sonication may enhance the extraction efficiency, but the temperature of the sample should then be monitored. In studies with radiolabeled compounds, sequential extractions should be performed until $<5 \%$ of the radioactivity released from the first extraction is obtained. This usually occurs between three and five extractions with one solvent system [65].

The selection of the proper organic solvents is a critical step. The physico-chemical properties of the analyte, i.e., its volatility, water solubility, the solubility in the organic solvent to be used, the $\mathrm{pKa}$, and the stability, as well as the test matrix properties (such as the moisture and organic matter content of soils and sediments), must be considered [66]. Properties of some extraction solvents and their relations to properties of analytes are given in Additional file 1: Tables S1 and S2. Some examples are presented in Table 2 how to remove extractable fractions from environmental matrices to obtain non-extractable residues.

Pure organic solvents should be avoided in the first extraction steps because molecules distributed in the interlayers of clay particles in soil may be entrapped by shrinking of the clay when water is removed. Therefore, in the first extraction steps, water-miscible organic solvents should be mixed with small volumes of water, followed by exhaustive extraction pure solvents (or solvent mixtures). Extracts should be combined and concentrated prior to radio-profiling for instance by radio-HPLC or radio-TLC.

Since transformation products of chemicals usually differ from the parent compound in terms of polarity (most often more polar, sometimes less polar) and chemical reactivity (as well as ecotoxicity), extraction procedures have to be developed during the course of a degradation study. An effective extraction solvent for the parent compound is usually not effective for transformation/degradation products. It is, therefore, not possible to define optimal extraction conditions at the beginning of the study and to keep this procedure for aged samples; exemptions are of course possible. Both 
Table 2 Some examples of conditions to remove extractable fractions from environmental matrices to obtain nonextractable residues

\begin{tabular}{|c|c|c|c|}
\hline Analyte & Matrix & Solvents and methods to remove extractable fractions & References \\
\hline Cyprodinil & Soil & Methanol & {$[35,45,71-73]$} \\
\hline Simazine & Compost & Methanol:water 9:1 (v:v) & [33] \\
\hline Sulfadiazine & Soil & Ethanol:water 9:1 (v:v), Soxhlet & {$[46,61]$} \\
\hline MCPA & Soil, clay & Methanol; dichloromethane, Soxhlet & [74] \\
\hline Nonylphenol & Soil, clay & Methanol; dichloromethane, Soxhlet & [36] \\
\hline Nonylphenol & Soil & Methanol and ethylacetate & [75] \\
\hline Difloxacin & Soil & Ethylacetate:methanol:water:ammonia 63:25:9:3 (v:v:v:v), ASE & [44] \\
\hline Metalaxyl & Soil, sand, silt, clay & Methanol, Soxhlet & [76] \\
\hline Clodinafop-propargyl & Sediment & Acetonitrile, Soxhlet & [77] \\
\hline 3,4-Dichloroaniline & Sediment & Methanol & [78] \\
\hline Isoproturon & Soil & Methanol, ASE & [79] \\
\hline Tetrabromobisphenol A & Soil & Methanol; methanol and ethylacetate & [80-82] \\
\hline Phenanthrene & Soil & Dichloromethane and acetone & [83] \\
\hline Cypermethrin & Soil & Acetonitrile + water $7+3(v+v)$ & [84] \\
\hline Cypermethrin & Soil & Cyclohexane:acetone, 1:1 (v:v) & [8] \\
\hline Ciprofloxacin & Soil & Ethylacetate, methanol, ammoniumhydroxide, ASE & [85] \\
\hline Imidacloprid & Soil & Methanol, water, $\mathrm{HCl}$, Soxhlet & [86] \\
\hline Imidacloprid & Soil & Acetonitrile, water, MAE & [87] \\
\hline Carbendazim & Soil & Methanol, Soxhlet & [88] \\
\hline Isoproturon & Soil & Acetone, Soxhlet & [89] \\
\hline Metalaxyl & Soil & Acetonitrile, water, ASE & [90] \\
\hline
\end{tabular}

polar and nonpolar solvents, or miscible solvent mixtures should be tested for extraction depending on the nature of the residues.

While any changes of the parent substance and of major transformation/degradation products by the chosen extraction method can be tested by corresponding control experiments, its effect regarding structural changes of the matrix is much more difficult to assess. Soil scientists claim that soil structure is even changed by different moisture contents and the quality of percolating water $[67,68]$. Therefore, any method to extract soil, even under "mild" conditions, will lead to some structural changes. This holds especially for using organic solvent mixtures, both at room temperature and elevated temperatures.

Exhaustive extraction Soxhlet extraction, accelerated solvent extraction (ASE) or pressurized liquid extraction (PLE), supercritical fluid extraction (SFE), or microwave-assisted extraction (MAE) of the particulate matrix remaining should subsequently be applied, eventually using suitable modifier solvents, to release part of the molecules strongly adsorbed to the matrix [69]. If feasible, extracts can be analyzed by the same methods used for the previous extractions.
Strongly acidic and alkaline solvents for release of the extractable fraction (with simultaneous partial humic compound extraction) need to be avoided since severe structural changes regarding the inorganic (acids) and organic (alkali) components of the matrix will occur.

The approach of the described extraction steps "Use of aqueous solutions to determine the amount of residues being easily desorbable", "Use of organic solvent mixtures to extract thoroughly the matrix" and "Exhaustive extraction" follows in principle that of Ortega-Calvo et al. [70] who suggests to use the extraction sequence aqueous solutions, passive sampling extractions (e.g., TENAX), organic solvents at room temperature and at elevated temperature (e.g., ASE), to obtain the matrix containing only NER. Each of the fractions obtained by the above extraction steps can be used to analyze the amounts and to identify the structures of the extractable fractions. The residues remaining after the extractions in the matrix are defined as non-extractable residues (NER), which may include also bioNER (type III). These NER, thus, should be analyzed for the different types of NER.

\section{Differentiation of NER types (see Fig. 1, Step 2)}

For performing Step 2 extractions, samples must be splitted into two aliquots or sub-samples because 
silylation [step "Differentiation and quantification of type I and type II NER by silylation of the matrix") and amino acid extraction [step "Quantification of type III NER (bioNER)"] are considered to be "destructive" methods and cannot be applied to the same sample sequentially.

Differentiation and quantification of type I and type II NER by silylation of the matrix Silylation is a gentle derivatization method and has been used for decades in synthetic and analytical chemistry. In the environmental context, this pragmatic approach can be applied for quantification of the two NER types I and II. However, it does not provide information about the chemical identity of the NER as long as the released residues are not characterized, for instance, by mass spectroscopic approaches. Each fraction derived from these procedures may also contain bioNER. It cannot be excluded that by silylation, some residual type I NER will remain in the matrix, although this seems rather unlikely, but should be investigated by repeating the silylation step. If some residual type I NER would remain after this derivatization method, this would lead to an underestimation of type I NER, which are basically the releasable part, and an overestimation of type II NER.

Silylation will replace the exchangeable hydrogen atoms of functional groups in the organic matrix-e.g., carboxylic, hydroxy or amino groups-with trimethylsilyl groups [91]. The silylation breaks hydrogen bonds between polar functional groups and changes the hydrophilicity of organic matter, resulting in a partial disintegration of the humic substances into smaller fragments, which have been held together in supramolecular aggregates by noncovalent interactions in the original sample. Labile test substances may also be destroyed by this method but this can be checked for the respective compounds. If NER are entrapped in the matrix (type I NER candidates), they are released after silylation, while NER formed by covalent binding (type II NER candidates) remain bound to the matrix. Both fractions can be quantified when radioactively labelled chemicals have been used. However, for the final determination of the type I or II NER extent, the amounts of included bioNER need to be evaluated. In the type I NER containing fraction, this can either be done by quantification of the parent substances and transformation products, e.g., by MS, or the amount of bioNER [53]. The type II NER containing fraction needs to be calculated by the total NER after exhaustive extraction minus total bioNER and identified type I NER. These data can be used as endpoint for quantification of type I and type II NER. The experimental steps in the silylation procedure were described in detail, e.g., by [33] or in a slightly modified form [83].
Quantification of type III NER (bioNER) Both labeling with radioactive $\left({ }^{14} \mathrm{C}\right)[53]$ and stable isotopes $\left({ }^{13} \mathrm{C},{ }^{15} \mathrm{~N}\right)$ [12] has been successfully applied to quantify the amounts of type III NER using the extraction method. Basically, the environmental matrix, e.g., soil, is hydrolyzed by concentrated $\mathrm{HCl}$ at elevated temperature. The matrix and particularly the proteins are destroyed under such harsh conditions and the hydrolyzed extract contains the released amino acids [38, 40-42, 85]. Based on amino acid detection of hydrolyzed proteins, the total living biomass (which is bioNER) of short-term experiments should be calculated by multiplying the amino acid amount by the factor of 2 , since the amount of proteins in living microbial biomass is generally around 50\% [92]. During microbial turnover of microbial biomass, however, the ratio bioNER to proteins decreases and approaches 1.11 for long-term experiments ( $\geq 120$ days) [54].

Uncertainties and limitations of the methods Methodological uncertainties come primarily from the procedures for removing the extractable residues to obtain the matrix containing only NER. Taking the paper from Barriuso et al. [11], the amounts of NER of pesticides vary strongly depending on the extraction procedures, with the largest variations of a factor up to 10 . To give few examples: the amounts of NER of imazosulfuron vary between 19 and $68 \%$ of the applied radioactivity, that of propoxycarbazone between 6 and $65 \%$, of propiconazole between 4 and $48 \%$. Another methodological uncertainty is the extraction procedures for investigation of NER (silylation for type I and type II NER differentiation and acidic hydrolysis for bioNER quantification): it is likely that silylation extracts and residues besides xenobiotic residues also contain bioNER, especially for compounds that are readily biodegraded. Therefore, type I non-extractable residues need to be investigated to address this uncertainty, but a method for analytical differentiation needs to be developed. Chemical analysis of type II NER, which are strongly bound and not releasable under physiological, natural conditions, is, however, not possible, i.e., the uncertainty of the apportionment of xenobiotic and biogenic residues in these fraction cannot be settled.

As a further uncertainty, neither the silylation method to distinguish type I and type II NER nor the method to identify bioNER type III have been standardized but rather represent methods derived from basic research. Structural identification of type I and type II residues is a technical challenge and laborious. As a pragmatic approach, the released amount of NER after silylation can be taken as type I NER, that remaining in the matrix as type II NER. Assuming that the relative amount of type III NER, which is determined independently by the 
described acidic hydrolysis method, is the same also in the type I and type II NER fractions, it is possible to estimate the absolute amounts of types I and II.

\section{Options for the assessment of the potential remobilization of total NER}

Many studies reveal that NER may become released under natural environmental conditions, such as the microbial activity in the rhizosphere of plants or in the digestive tract of animals, but the released residues enter a matrix with degrading activity and may subsequently be transformed or partly mineralized. Release of NER has been observed also by applying artificial conditions that, however, will never (e.g., EDTA addition) or only rarely happen under natural conditions.

Several authors investigated the stability of NER formed during microbial turnover of environmental contaminants such as PAH [93] and TNT [94, 95]. NER derived from ${ }^{14} \mathrm{C}$-labelled anthracene or the explosive ${ }^{14} \mathrm{C}$-2,4,6-trinitrotoluene (TNT) in soil were analyzed after simulation of extreme physical, chemical or biological conditions in a systematic manner. These authors used the following treatments for the residue containing soils.

i. Physical treatment for simulating climatic effects by freezing and thawing $[96,97]$, wetting and drying or by changing the soil texture via ploughing or grinding [93];

ii. Chemical treatment, the extraction of soil with the metal complexing agent EDTA [98] for estimating the effects of bivalent cations on the aggregation of macromolecular soil organic compounds and the extraction of soil with hot or acidified $\mathrm{H}_{2} \mathrm{O}$ simulating a millennial rain event and the acid rain impact on the release of NER [99].

iii. Biological treatment, the simulation of increased turnover of SOM and the NER by addition of compost $[23,100]$ or incubation of the soil containing NER with ligninolytic fungi [101-103].

It has to be taken in mind that remobilization experiments are an operational approach, and the absence of remobilization is no conclusive evidence for covalent binding.

\section{The microbial turnover to biomass (MTB) for predicting NER formation}

Chemicals that are easily biodegradable show high mineralization rates and are, thus, prone to formation of biogenic NER, whereas those which are poorly biodegradable (persistent) with low mineralization rates will mainly form type I and type II NER [12].

A clear correlation has been recently established between released $\mathrm{CO}_{2}$ (as indicator of microbial activity and mineralisation), biomass yield, and biogenic NER formation [104]. This relation can be used as a screening tool or indicator for bioNER formation in a two-step process: first, the theoretical growth yield is estimated from thermodynamics and molecule structure. Second, the yield together with the information about $\mathrm{CO}_{2}$ production (determined experimentally in a biodegradation test) is used to calculate the microbial biomass growth. If the experiment is long term, then also the biomass turnover in the microbial food chain is considered. The sum of living and dead biomass plus organic matter originating from this dead biomass contributes to bioNER [54].

Microbial growth and degradation of the test chemicals lead to the incorporation of labeled carbon into the microbial mass, resulting in biogenic NER. The MTB approach needs minimum input data (Gibbs free energies of products and educts, molar mass, the empirical formula of the chemical, and the number of $\mathrm{CH}$ bonds) which are readily available. The microbial growth yields of 40 organic chemicals of environmental concern (including 31 pesticides) were recently estimated. The results were compared to experimental values and the results of other methods for yield estimation that are available in the literature. With the theoretical biomass yield and using the released $\mathrm{CO}_{2}$ as a measure for microbial activity, a range for the formation of biogenic NER could be predicted. For the majority of the pesticides, a considerable fraction of the NER was estimated to be biogenic.

The MTB yield estimate has shown the best performance for the yield prediction of xenobiotics but still had a mean average error (in comparison to experimental data which may also have some error) of $49 \%$ with both overestimation and underestimation [105]; the high deviation is due to failure in few cases, and reasons for the failure could be identified. Validation with ${ }^{13} \mathrm{C}$-studies showed good agreement to measured growth yields of 2,4-D and ibuprofen [54] which form much higher bioNER than type I and II NER; more such data will be helpful and are currently under production.

The MTB tool can be used in the persistence assessment as a screening tool for the estimation of the likeliness of type III NER versus type I and II (xenoNER). The MTB yield method is quite new and experience with tested chemicals is still limited. Until sufficient (and supporting) experience has been gained, the method should only be used as an indicator and not as a definitive proof for bioNER formation; if the MTB method 
indicates relevant bioNER formation, then the formation of bioNER should be tested experimentally.

A conceptual sketch on the characterization of NER is provided in Fig. 2.

\section{Concepts for assessing the role of NER in the regulatory context \\ NER in P assessment}

As shown, the experimental and theoretical differentiation of NER types is nowadays possible and should be considered in the persistence assessment of chemicals. If the likeliness for the formation of biogenic NER is high (presumably derived from the in silico assessment with MTB and the confirming mineralisation in the fate assessment), the consideration of NER as parent substances or primary transformation/degradation products is not justified and here the analysis of bioNER is suggested. For the remaining NER of type I (for type II only if there are indications for remobilisation potential), a remobilization assessment is suggested (see Table 1). A guide value for remobilization of NER can be given: only if no or very low amounts of residues are released (for soil organic matter, $<2 \% \mathrm{C} / \mathrm{a}$ ), we consider this as no remobilization. The turnover of $2 \% \mathrm{C} /$ year is the average respiration of a living soil including soil organic matter under aerobic condition [106, 107]. Conant et al. [106]. assumed that $5-15 \%$ of SOM, i.e., the readily degradable, "fresh" organic carbon pool, is decomposed within months to years, $40-50 \%$ of SOM, the intermediate pool, within years to decades, and $40-50 \%$ of SOM, the stable "old" organic matter, within decades to centuries.

Based on the present scientific analysis of the NER formation and the screening of the available related documents, it can be stated that characterization of NER can be embedded in the general persistence assessment of all chemicals. We propose to generally consider unknown total NER as remobilizable parent or transformation products, if no additional information is available. If clear indications for bioNER and also for covalently bound type II NER are available (unless there exist indications for a remobilization potential), these NER can be considered as 'safe sink.' Covalently bound NER, in particular if multi-covalently bound, are believed to have very low remobilization potential since such bonds are considered to be rather stable under physiological conditions [91, 93, 108].

The MTB approach [54] is suggested to be used for the general estimation of the biomass yield and the bioNER formation potential to obtain information before setting required OECD degradation or fate simulation tests. Indications for bioNER can be cross-validated by assessing $\mathrm{CO}_{2}$ formation in degradation experiments, or the bioNER can be analytically confirmed. Vice versa, dominantly NER type I or II forming chemicals can be identified, which may not need further evaluation of bioNER. This approach is very important for not wasting time with inappropriate testing of a certain chemical without a specific NER focus and is also helpful for the interpretation of results derived from these tests. The general concept of the MTB application is to consider the total NER minus potential bioNER as the amount of type I + II NER. Type $I$ is considered to include remobilization potential; whereas type II is considered to be irreversibly bound (unless there are indications for the opposite). The MTB yield estimation can also be applied to gain information about $\mathrm{P}$ indication-very low biomass yields are an indicator for persistence.

\section{How to deal with complex mixtures and natural compounds?}

Persistence assessment of mixtures and substances of unknown or variable composition, complex reaction products or biological materials (UVCBs) is a challenge (ECHA_2017_R.11 Section R11.4.2.2). Approaches rely on constituent profiling, identification of known constituents, or block profiling (functional blocks), if no known constituent can be identified. Our proposed approach for NER characterisation can only be applied for 'identified constituents' generally based on the application of isotope labelled compounds. In a broader sense, it may

\section{Characterization of NER}

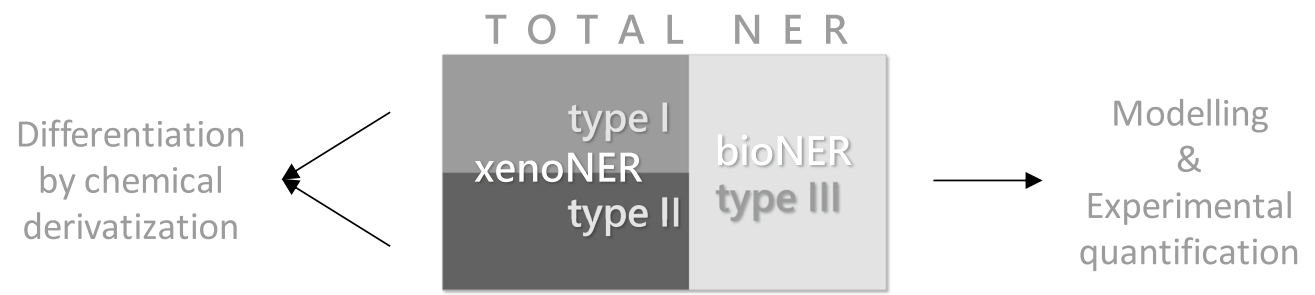

Fig. 2 NER characterization concept. Experimental and modeling steps to differentiate the three types of NER 
also be applied to mixtures and substances of unknown composition as long as known compounds or constituent blocks, or the compounds of most critical concern can be identified. If the most critical constituent can be identified, the general suggested approach of NER characterisation is valid. If feasible, the fate and turnover of the compounds in the mixture should always be compared to the behavior of the pure compounds to evaluate additional effects caused by the mixture. If only the 'whole substance approach' is applicable without supply of any labelled compound, the NER cannot be quantified.

The MTB approach can be applied to each constituent separately, or to a block of constituents, if a common chemical structure can be identified. Then a lumped biomass yield can be calculated. If the physical and chemical properties of the mixtures are highly different from the known constituents, for example for specific compounds in non-aqueous phase liquids (NAPLs), the fate and distribution behavior can be affected [12, 109]. NAPLs may cause mass transfer problems and result in not fully developed biomass yields.

\section{Recommendations for further research}

There are multiple causes of diverging results in fate studies of chemicals even for one compound in one test system and this is actually a very difficile problem and cannot be solved with general considerations. Adding an additional analytical parameter like NER makes the situation even more complex. Therefore, only a weight of evidence evaluation of each test result is possible and needs to be taken with care and expertise.

\section{Types I and II NER (xenoNER)}

The following investigations should be performed with environmental matrices which have been thoroughly extracted and contain NER only. The release of parent substances and transformation/degradation products should be systematically studied ("Options for the assessment of the potential remobilisation of total NER" section), also with respect to the question whether this release is associated with the degradation rate of natural soil organic matter.

In cases where type II NER has been unambiguously demonstrated, cleaving of covalent ester-bonds by labelled water $\left(\mathrm{H}_{2}^{18} \mathrm{O}\right)$ or sodium hydroxide $\left(\mathrm{Na}^{18} \mathrm{OH}\right) \mathrm{can}$ clearly prove covalent binding as shown for the transformation/degradation products of DDT and metalaxyl which were bound by ester-linkage to humic matter [52]. However, other types of covalent bonds, like Michael adducts or Schiff base adducts, cannot be investigated by this methodology.

\section{Type III NER (biogenic residues)}

Predictions of bioNER by MTB modeling need to be validated by experimental investigations of more chemical substances. Also, the effect of repeated applications of a chemical to soil (as in case of spray series of pesticides) on the formation of type III NER should be further investigated: adaptation of soil microorganisms and accelerated degradation has been described [110-112] but so far not with respect to NER formation. Principally, such effects can be considered by the MTB method.

\section{General issues}

There is still a set of issues that remain to be investigated regarding NER characterization.

- There is urgent need for standardization of the NER extraction methods. Regular ringtests should be performed to validate the proposed silylation technique for distinction of type I and type II NER as well as the hydrolysis method for determining bioNER. The efficiency of the silylation method to release all type I NER should be tested, e.g., by repeating silylation of the matrix.

- There is also need for standardization of NER remobilization assessment methods ("Options for the assessment of the potential remobilisation of total NER" section), which are also less sufficiently described in the literature. Experiments should be performed with a set of chemicals covering various functional groups.

- The relationship between extraction technique and bioavailability: there are currently several methods available to assess the bioavailability or bioaccessibility of chemicals in environmental matrices [66]; however, the release and the accessibility on the long run or under changes of the environmental conditions are still an open question.

- The potential correlation of the bioavailability (e.g., by passive sampling) and ecotoxicity of NER, especially of those chemicals forming significant amounts of type I NER should be studied.

- A special case of NER may be the conjugates of chemicals (pharmaceuticals, pesticides) in NER assessment, in particular if entering the environment by activated sludge or manure. These are no NER in sensu stricto but they may also become associated with particulate matter in environmental systems. The remobilization potential of such compounds needs to be tested.

- Special consideration has to be given to the class of poorly water-soluble substances with log Kow values above about 6 , which have a high tendency to adsorb to particulate matter like soil or sediment. 
These compounds quickly partition from the aqueous phase to pores of the humic matter becoming strongly sorbed or sequestered (type I NER). Even if the inherent biodegradability is high, they become rather persistent in the sequestered state if desorption rates are very slow. Persistence is clearly influenced by partitioning to particulate matrices as has been shown by many examples: even biodegradable substances like proteins persist after immobilization to a solid matrix.

- Concepts to describe the competing kinetics of adsorption, sequestration and biodegradation kinetics are available, and at least one model exists that can, with reasonable input data, estimate simultaneous formation of type I NER and type III bioNER, namely the unified model for sorption and biodegradation $[12,54]$. However, few studies have been performed where detailed experimental data has been used for comparison to simulation results, and more research is helpful for confirmation and verification of model concept and output. Similarly, mathematical tools that simulate the outcome of OECD tests, e.g., [113-115], would be useful both for interpretation and confirmation of the test results. The development and test of such models are recommended.

\section{Additional file}

Additional file 1: Table S1. Properties of typical organic solvents and water. Table S2. Relative polarity of chemical classes and examples of typical extraction solvents; also mixtures of solvents can be used. The selection is not exclusive and several solvents listed cover a range of chemical classes to be extracted.

\section{Abbreviations}

ASE: accelerated solvent extraction (extraction with the option of elevated temperature and pressure (cf. PLE); $\mathrm{BBr}_{3}$ : borontribromide; bioNER: biogenic NER; DT50: time taken for $50 \%$ of substance to disappear from a compartment by dissipation processes (dissipation half-life); DegT50: time taken for $50 \%$ of substance to disappear from a compartment due to degradation processes alone (degradation half-life); ECHA: European Chemicals Agency; GC-MS: gas chromatography coupled to mass spectrometry detection; HPLC-MS, HPLCUV: high performance liquid chromatography coupled to mass spectrometry detection or UV detector, respectively; KOH: potassium hydroxide; LSC: a method to quantify radioactivity by mixing a radioactive sample with a liquid scintillator in a solvent and counting the resulting photon emissions. The photons are released from scintillator molecules after excitation by the radioactive material (such as beta particles emission from ${ }^{14} \mathrm{C}$-labeled material). Alternatively, a radioactive sample in a solvent can be passed through a matrix with immobilized scintillators: MAE: microwave-assisted extraction; MTB: microbial turnover to biomass (model to predict formation of bioNER); NER: non-extractable residues; NER type I: sequestered, entrapped NER; NER type II: covalently bound NER; NER type III: biogenic NER (bioNER); NMR: nuclear magnetic resonance; PLE: pressurized liquid extraction at elevated pressure and temperature. This method of extraction is equivalent to the accelerated solvent extraction (ASE); PLFA: phospholipid fatty acids, components of every cell membrane; Radio-HPLC: high-performance liquid chromatography coupled to a radioactivity detector, for instance for profiling ${ }^{14} \mathrm{C}$-labeled residues in degradation studies; Radio-TLC: thin layer chromatography and subsequent analysis of radiolabeled residues, e.g., ${ }^{14} \mathrm{C}$-residues, on the plate by a radioactivity detector; $\mathrm{RuO}_{4}$ : ruthenium tetroxide; SFE: supercritical fluid extraction; extraction of mostly a solid matrix, like soil or sediment, using supercritical fluids as extractants. Supercritical fluids share the properties of liquids (with high dissolving power) and gases (with high diffusion coefficients) above a certain temperature and pressure. Often, carbon dioxide is used as supercritical fluid, sometimes modified by co-solvents like ethanol, because the critical temperature of $\mathrm{CO}_{2}\left(31^{\circ} \mathrm{C}\right)$ and critical pressure (74 bar) are easily achieved; SOM: soil organic matter; xenoNER: NER containing xenobiotic molecules, i.e., the parent substance and transformation products; TLC: thin layer chromatography, for instance two-dimensional (2D-TLC); TMAH: tetramethylammonium hydroxide, derivatization agents; UVCB: substances of unknown or variable composition, complex reaction products or biological materials.

\section{Authors' contributions}

All authors contributed equally to the study and the paper. All authors read and approved the final manuscript.

\section{Author details \\ ${ }^{1}$ Institute for Environmental Research, RWTH Aachen University, Worringer- weg 1, 52074 Aachen, Germany. ${ }^{2}$ Department Environmental Biotechnol- ogy, Helmholtz Centre for Environmental Research, UFZ, Permoserstraße15, 04318 Leipzig, Germany. ${ }^{3}$ Department of Environmental Engineering, Techni- cal University of Denmark, Bygningstorvet bd. 115, 2800 Kongens Lyngby, Denmark.}

\section{Acknowledgements}

We gratefully acknowledge extensive and fruitful discussions with colleagues from ECHA—Lucie Ribeiro, Anu Kapanen, Joanna Peltola-Thies, and Vincent Bonnomet.

\section{Competing interests}

The authors declare that they have no competing interests.

\section{Availability of data and materials}

The datasets used and/or analyzed during the current study are available from the corresponding author on reasonable request.

\section{Consent for publication}

All authors agreed to publish the paper.

\section{Ethics approval and consent to participate}

Ethics approval: not applicable. All authors agreed to contribute to the study and to the paper.

\section{Funding}

The study was financially supported by ECHA.

\section{Publisher's Note}

Springer Nature remains neutral with regard to jurisdictional claims in published maps and institutional affiliations.

Received: 20 October 2018 Accepted: 4 December 2018

Published online: 17 December 2018

\section{References}

1. EC_528_2012. Regulation (EU) No 528/2012 of the European Parliament and of the Council of 22 May 2012 concerning the making available on the market and use of biocidal products. https://eur-lex.europ a.eu/LexUriServ/LexUriServ.do?uri=OJ:L:2012:167:0001:0123:EN:PDF. Accessed 1 Dec 2018

2. EC_1107_2009. Regulation (EC) No 1107/2009 of the European Parliament and of the Council of 21 October 2009 concerning the placing of plant protection products on the market. https://eur-lex.europ a.eu/LexUriServ/LexUriServ.do?uri=OJ:L:2009:309:0001:0050:EN:PDF. Accessed 1 Dec 2018 
3. EC_1907_2006. Regulation (EC) No 1907/2006 of the European Parliament and of the Council of 18 December 2006 concerning the registration, evaluation, authorisation and restriction of chemicals (REACH). https://eur-lex.europa.eu/legal-content/EN/TXT/PDF/?uri=CELEX :02006R1907-20140410\&from=EN. Accessed 1 Dec 2018

4. EC_726_2004. Regulation (EC) No 726/2004 of the European Parliament and of the council of 31 March 2004 laying down Community procedures for the authorisation and supervision of medicinal products for human and veterinary use and establishing a European Medicines Agency. https://ec.europa.eu/health/sites/health/files/files/eudralex/ vol-1/reg_2004_726/reg_2004_726_en.pdf. Accessed 1 Dec 2018

5. EC_27_2004. Directive 2004/27/EC of the European Parliament and of the council of 31 March 2004 amending Directive 2001/83/EC on the Community code relating to medicinal products for human use. https://ec.europa.eu/health/sites/health/files/files/eudralex/vol-1/ dir_2004_27/dir_2004_27_en.pdf. Accessed 1 Dec 2018

6. EC_28_2004. Directive 2004/28/EC of the European parliament and of the council of 31 March 2004 amending Directive 2001/82/EC on the Community code relating to veterinary medicinal products. https://ec.europa.eu/health/sites/health/files/files/eudralex/vol-5/ dir_2004_28/dir_2004_28_en.pdf. Accessed 1 Dec 2018

7. ECHA_2017_R.7b. Guidance on information requirements and chemical safety assessment, Chapter R.7b: Endpoint specific guidance, version 4.0, June 2017. https://echa.europa.eu/documents/10162/13632/infor mation_requirements_r7b_en.pdf. Accessed 1 Dec 2018

8. ECHA_2017_R.7c. Guidance on information requirements and chemical safety assessment, Chapter R.7c: Endpoint specific guidance, version 3.0, June 2017. https://echa.europa.eu/documents/10162/13632/infor mation_requirements_r7c_en.pdf. Accessed 1 Dec 2018

9. ECHA_2017_R.11. Guidance on information requirements and chemical safety assessment, Chapter R.11: Endpoint specific guidance (PBT/vPvB assessment), version 3.0, June 2017. https://echa.europa.eu/docum ents/10162/13632/information_requirements_r11_en.pdf. Accessed 1 Dec 2018

10. Kästner M, Trapp S, Schäffer A (2018) Consultancy services to support ECHA in improving the interpretation of non-extractable residues (NER) in degradation assessment-a discussion paper (final report)

11. Barriuso E, Benoit P, Dubus IG (2008) Formation of pesticide nonextractable (bound) residues in soil: magnitude, controlling factors and reversibility. Environ Sci Technol 42(6):1845-1854

12. Kaestner M, Nowak KM, Miltner A, Trapp S, Schaeffer A (2014) Classification and modelling of nonextractable residue (NER) formation of xenobiotics in soil—a synthesis. Crit Rev Environ Sci Technol 44(19):2107-2171

13. Roberts TR (1984) Non-extractable pesticide residues in soils and plants. Pure Appl Chem 56(7):945-956

14. DG_SANCO_2012. Working document on "Evidence needed to identify POP, PBT and vPVB properties for pesticides". https://ec.europa.eu/food/ sites/food/files/plant/docs/pesticides_ppp_app-proc_guide_fate_ evidence_identify-pop-pbt-vpvb-props.pdf. Accessed 1 Dec 2018

15. FOCUS, Update of FOCUS (2006) Guidance document on estimating persistence and degradation kinetics from environmental fate studies on pesticides in EU registration. Report of the FOCUS work group on degradation kinetics, EC document reference Sanco/10058/2005 version 2.0, 2014. p 434. https://esdac.jrc.ec.europa.eu/public_path/proje cts_data/focus/dk/docs/finalreportFOCDegKinetics.pdf. Accessed 1 Dec 2018

16. EC_1907_2006. Regulation no. 1907/2006 of the European Parliament and of the Council concerning the registration, evaluation, authorization and restriction of chemicals. https://eur-lex.europa.eu/legal -content/EN/TXT/PDF/?uri=CELEX:02006R1907-20140410\&from=EN. Accessed 1 Dec 2018

17. Fenner K, Canonica S, Wackett LP, Elsner M (2013) Evaluating pesticide degradation in the environment: blind spots and emerging opportunities. Science 341(6147):752-758

18. Gavrilescu M (2005) Fate of pesticides in the environment and its bioremediation. Eng Life Sci 5(6):497-526

19. Benoit P, Barriuso E (1997) Fate of ${ }^{14} C$-ring-labeled 2,4-D, 2,4-dichlorophenol and 4-chlorophenol during straw composting. Biol Fertil Soils 25(1):53-59
20. Mordaunt CJ, Gevao B, Jones KC, Semple KT (2005) Formation of nonextractable pesticide residues: observations on compound differences, measurement and regulatory issues. Environ Pollut 133(1):25-34

21. Craven A (2000) Bound residues of organic compounds in the soil: the significance of pesticide persistence in soil and water: a European regulatory view. Environ Pollut 108(1):15-18

22. Gevao B, Jones K, Semple K, Craven A, Burauel P (2003) Nonextractable pesticide residues in soil. Environ Sci Technol 37(7):138a-144a

23. Barriuso E, Houot S, SerraWittling C (1997) Influence of compost addition to soil on the behaviour of herbicides. Pestic Sci 49(1):65-75

24. Loiseau L, Barriuso E (2002) Characterization of the atrazine's bound (nonextractable) residues using fractionation techniques for soil organic matter. Environ Sci Technol 36(4):683-689

25. Gevao B, Semple KT, Jones KC (2000) Bound pesticide residues in soils: a review. Environ Pollut 108(1):3-14

26. Barraclough D, Kearney T, Croxford A (2005) Bound residues: environmental solution or future problem? Environ Pollut 133(1):85-90

27. Khan SU, Dupont S (1987) Bound pesticide residues and their bioavailability. In: Greenhalgh R, Roberts TR (eds) Pesticide science and technology. Blackwell Scientific Publications, Oxford, pp 417-420

28. Pignatello JJ (1989) Sorption dynamics of organic compounds in soils and sediments. In: Sawhney BL, Brown BK (eds) Reactions and movements of organic chemicals in soil. SSSA and ASA Publisher, Madison, pp 45-79

29. Senesi N (1992) Binding mechanisms of pesticides to soil humic substances. Sci Total Environ 123:63-76

30. Wais A (1998) Non-extractable residues of organic xenobiotics in soils_-a review. In: Fuhr F, Ophoff H (eds) Pesticide bound residues in soil. Wiley, Weinheim, pp 5-17

31. Führ F, Ophoff H, Burauel P, Wanner U, Haider K (1998) Modification of definition of bound residues. In: Fuhr F, Ophoff H (eds) Pesticide bound residues in soil. Wiley, Weinheim, pp 175-176

32. OECD Guidelines for the testing of chemicals, Section 3, environmental fate and behaviour http://www.oecd-library.org/environment/ oecd-guidelines-for-the-testing-of-chemicals-section-3-degradatio n-and-accumulation_2074577x. Accessed 1 Dec 2018

33. Berns A, Vinken R, Bertmer M, Breitschwerdt A, Schaffer A (2005) Use of $\mathrm{N}$-15-depleted artificial compost in bound residue studies. Chemosphere 59(5):649-658

34. Berns AE, Bertmer M, Schaffer A, Meier RJ, Vereecken H, Lewandowski $H$ (2007) The N-15-CPMAS spectra of simazine and its metabolites: measurements and quantum chemical calculations. Eur J Soil Sci 58(4):882-888

35. Ertunc T, Schmidt B, Kuhn H, Bertmer M, Schaffer A (2004) Investigation on the chemical structure of nonextractable residues of the fungicide cyprodinil in spring wheat using C-13-C1-phenyl-cyprodinil on C-13-depleted plants - an alternative approach to investigation nonextractable residues. J Environ Sci Health B 39(5-6):689-707

36. Riefer P, Klausmeyer T, Adams A, Schmidt B, Schaffer A, Schwarzbauer J (2013) Incorporation mechanisms of a branched nonylphenol isomer in soil-derived organo-clay complexes during a 180-day experiment. Environ Sci Technol 47(13):7155-7162

37. Girardi C, Nowak KM, Carranza-Diaz O, Lewkow B, Miltner A, Gehre M, Schaffer A, Kastner M (2013) Microbial degradation of the pharmaceutical ibuprofen and the herbicide 2,4-D in water and soil- —use and limits of data obtained from aqueous systems for predicting their fate in soil. Sci Total Environ 444:32-42

38. Nowak KM, Girardi C, Miltner A, Gehre M, Schaffer A, Kastner M (2013) Contribution of microorganisms to non-extractable residue formation during biodegradation of ibuprofen in soil. Sci Total Environ 445:377-384

39. Nowak KM, Kouloumbos VN, Schaffer A, Corvini PFX (2008) Effect of sludge treatment on the bioaccumulation of nonylphenol in grass grown on sludge-amended soil. Environ Chem Lett 6(1):53-58

40. Nowak KM, Miltner A, Gehre M, Schaffer A, Kastner M (2011) Formation and fate of bound residues from microbial biomass during 2,4-D degradation in soil. Environ Sci Technol 45(3):999-1006

41. Wang S, Seiwert B, Kastner M, Miltner A, Schaffer A, Reemtsma T, Yang Q, Nowak KM (2016) (Bio)degradation of glyphosate in water-sediment microcosms-a stable isotope co-labeling approach. Water Res 99:91-100 
42. Wang SZ, Miltner A, Kastner M, Schaffer A, Nowak KM (2017) Transformation of metamitron in water-sediment systems: detailed insight into the biodegradation processes. Sci Total Environ 578:100-108

43. Wang SZ, Miltner A, Nowak KM (2017) Identification of degradation routes of metamitron in soil microcosms using C-13-isotope labeling. Environ Pollut 220:927-935

44. Junge T, Classen N, Schaffer A, Schmidt B (2012) Fate of the veterinary antibiotic C-14-difloxacin in soil including simultaneous amendment of pig manure with the focus on non-extractable residues. J Environ Sci Health B 47(9):858-868

45. Dec J, Haider K, Schaffer A, Fernandes E, Bollag JM (1997) Use of a silylation procedure and C-13-NMR spectroscopy to characterize bound and sequestered residues of cyprodinil in soil. Environ Sci Technol 31(10):2991-2997

46. Junge T, Meyer KC, Ciecielski K, Adams A, Schaffer A, Schmidt B (2011) Characterization of non-extractable C-14- and C-13-sulfadiazine residues in soil including simultaneous amendment of pig manure. J Environ Sci Health B 46(2):137-149

47. Richnow HH, Seifert R, Hefter J, Kastner M, Mahro B, Michaelis W (1994) Metabolites of xenobiotica and mineral oil constituents linked to macromolecular organic matter in polluted environments. Org Geochem 22(3-5):671-681

48. Wanner U, Fuhr F, deGraaf AA, Burauel P (2005) Characterization of nonextractable residues of the fungicide dithianon in soil using C-13/C14-labelling techniques. Environ Pollut 133(1):35-41

49. Kong DY, Xia Q, Liu GQ, Huang QG, Lu JH (2013) Covalent bonding of chloroanilines to humic constituents: pathways, kinetics, and stability. Environ Pollut 180:48-54

50. Kronimus A, Schwarzbauer J, Ricking M (2006) Analysis of nonextractable DDT-related compounds in riverine sediments of the Teltow Canal, Berlin, by pyrolysis and thermochemolysis. Environ Sci Technol 40(19):5882-5890

51. Thorn KA, Pettigrew PJ, Goldenberg WS (1996) Covalent binding of aniline to humic substances. 2. N-15 NMR studies of nucleophilic addition reactions. Environ Sci Technol 30(9):2764-2775

52. Kalathoor R, Zeiner M, Schmidt B, Schaffer A, Schwarzbauer J (2015) First evidence for covalent linkage of acidic metabolites of metalaxyl and DDT as non-extractable pesticide residues in soil and sediment. Environ Chem Lett 13(4):431-437

53. Possberg C, Schmidt B, Nowak K, Telscher M, Lagojda A, Schaeffer A (2016) Quantitative identification of biogenic nonextractable pesticide residues in soil by C-14-analysis. Environ Sci Technol 50(12):6415-6422

54. Trapp S, Brock AL, Nowak K, Kästner M (2018) Prediction of the formation of biogenic non-extractable residues during degradation of environmental chemicals from biomass yields. Environ Sci Technol 52:663-672

55. Wang SF, Sun FF, Wang YF, Wang LH, Ma YN, Kolvenbach BA, Corvini PFX, Ji R (2017) Formation, characterization, and mineralization of bound residues of tetrabromobisphenol A (TBBPA) in silty clay soil under oxic conditions. Sci Total Environ 599:332-339

56. Peijnenburg W, Zablotskaja M, Vijver MG (2007) Monitoring metals in terrestrial environments within a bioavailability framework and a focus on soil extraction. Ecotoxicol Environ Saf 67(2):163-179

57. Houba VJG, Temminghoff EJM, Gaikhorst GA, van VarkW (2000) Soil analysis procedures using $0.01 \mathrm{M}$ calcium chloride as extraction reagent. Commun Soil Sci Plant Anal 31(9-10):1299-1396

58. Regitano JB, Koskinen WC, Sadowsky MJ (2006) Influence of soil aging on sorption and bioavailability of simazine. J Agric Food Chem 54(4):1373-1379

59. Alonso DG, Oliveira RS, Hall KE, Koskinen WC, Constantin J, Mislankar S (2015) Changes in sorption of indaziflam and three transformation products in soil with aging. Geoderma 239:250-256

60. Paszko T (2014) Adsorption, degradation and mobility of carbendazim in profiles of Polish mineral soils. Geoderma 226:160-169

61. Schmidt B, Ebert J, Lamshoft M, Thiede B, Schumacher-Buffel R, Ji R, Corvini PFX, Schaffer A (2008) Fate in soil of C-14-sulfadiazine residues contained in the manure of young pigs treated with a veterinary antibiotic. J Environ Sci Health B 43(1):8-20

62. Lanno R, Wells J, Conder J, Bradham K, Basta N (2004) The bioavailability of chemicals in soil for earthworms. Ecotoxicol Environ Saf 57(1):39-47
63. Katayama A, Bhula R, Burns GR, Carazo E, Felsot A, Hamilton D, Harris C, Kim YH, Kleter G, Koedel W, Linders J, Peijnenburg J, Sabljic A, Stephenson RG, Racke DK, Rubin B, Tanaka K, Unsworth J, Wauchope RD (2010) Bioavailability of xenobiotics in the soil environment. In: Whitcare DM (ed) Reviews of environmental contamination and toxicology, vol 203. Springer, New York, pp 1-86

64. Kemmerich M, Bernardi G, Adaime MB, Zanella R, Prestes OD (2015) A simple and efficient method for imidazolinone herbicides determination in soil by ultra-high performance liquid chromatographytandem mass spectrometry. J Chromatogr A 1412:82-89

65. Nießner R, Schäffer A (2017) Organic trace analysis (chapter 6). De Gruyter, Berlin

66. Ecetoc_2013_R117. Technical report 117, understanding the relationship between the extraction technique and bioavailability. http:// www.ecetoc.org/wp-content/uploads/2014/08/ECETOC-TR-117-Understanding-the-relationship-between-extraction-technique-andbioavailability.pdf. Accessed 1 Dec 2018

67. Ben-Hur M, Yolcu G, Uysal H, Lado M, Paz A (2009) Soil structure changes: aggregate size and soil texture effects on hydraulic conductivity under different saline and sodic conditions. Aust J Soil Res 47(7):688-696

68. Emdad MR, Raine SR, Smith RJ, Fardad H (2004) Effect of water quality on soil structure and infiltration under furrow irrigation. Irrig Sci 23(2):55-60

69. EPA (2014) Guidance for addressing unextracted pesticide residues in laboratory studies. https://www.epa.gov/pesticide-science-and-asses sing-pesticide-risks/guidance-addressing-unextracted-pesticideresidues. Accessed 1 Dec 2018

70. Ortega-Calvo J-J, Harmsen J, Parsons JR, Semple KT, Aitken MD Ajao C, Eadsforth C, Galay-Burgos M, Naidu R, Oliver R, Peijnenburg WJGM, Roembke J, Streck G, Versonnen B (2015) From bioavailability science to regulation of organic chemicals. Environ Sci Technol 49(17):10255-10264

71. Dec J, Haider K, Rangaswamy V, Schaffer A, Fernandes E, Bollag JM (1997) Formation of soil-bound residues of cyprodinil and their plant uptake. J Agric Food Chem 45(2):514-520

72. Dec J, Haider K, Benesi A, Rangaswamy V, Schaffer A, Plucken U, Bollag JM (1997) Analysis of soil-bound residues of C-13-labeled fungicide cyprodinil by NMR spectroscopy. Environ Sci Technol 31(4):1128-1135

73. Sapp M, Ertunc T, Bringmann I, Schaffer A, Schmidt B (2004) Characterization of the bound residues of the fungicide cyprodinil formed in plant cell suspension cultures of wheat. Pest Manag Sci 60(1):65-74

74. Riefer P, Klausmeyer T, Schwarzbauer J, Schaffer A, Schmidt B, Corvini PFX (2011) Rapid incorporation and short-term distribution of a nonylphenol isomer and the herbicide MCPA in soil-derived organo-clay complexes. Environ Chem Lett 9(3):411-415

75. Shan J, Jiang BQ, Yu B, Li CL, Sun YY, Guo HY, Wu JC, Klumpp E, Schaffer A, Ji R (2011) Isomer-specific degradation of branched and linear 4-nonylphenol isomers in an oxic soil. Environ Sci Technol 45(19):8283-8289

76. Botterweck J, Schmidt B, Schwarzbauer J, Kalathoor R, Schaffer A (2014) Enhanced non-extractable residue formation of C-14-metalaxyl catalyzed by an immobilized laccase. Biol Fertil Soils 50(7):1015-1024

77. Yuan Y, Weitzel P, Schaffer A, Schmidt B (2015) Metabolic fate of the C-14-labeled herbicide clodinafop-propargyl in a sediment-water system. J Environ Sci Health B 50(8):533-543

78. Yuan Y, Zhang P, Schaffer A, Schmidt B (2017) 3,4-Dichloroaniline revisited: a study on the fate of the priority pollutant in a sediment-water system derived from a rice growing region in Italy. Sci Total Environ 574:1012-1020

79. Li RY, Dorfler U, Schroll R, Munch JC (2016) Biodegradation of isoproturon in agricultural soils with contrasting $\mathrm{pH}$ by exogenous soil microbial communities. Soil Biol Biochem 103:149-159

80. Gu J, Jing Y, Ma Y, Sun F, Wang L, Chen J, Guo H, Ji R (2017) Effects of the earthworm Metaphire guillelmi on the mineralization, metabolism, and bound-residue formation of tetrabromobisphenol A (TBBPA) in soil. Sci Total Environ 595:528-536

81. Liu J, Wang YF, Jiang BQ, Wang LH, Chen JQ, Guo HY, Ji R (2013) Degradation, metabolism, and bound-residue formation and release 
of tetrabromobisphenol A in soil during sequential anoxic-oxic incubation. Environ Sci Technol 47(15):8348-8354

82. Li FJ, Wang JJ, Jiang BQ, Yang X, Nastold P, Kolvenbach B, Wang LH, Ma YN, Corvini PFX, Ji R (2015) Fate of tetrabromobisphenol A (TBBPA) and formation of ester- and ether-linked bound residues in an oxic sandy soil. Environ Sci Technol 49(21):12758-12765

83. Wang YF, Xu J, Shan J, Ma YN, Ji R (2017) Fate of phenanthrene and mineralization of its non-extractable residues in an oxic soil. Environ Pollut 224:377-383

84. Roberts TR, Standen ME (1981) Further studies of the degradation of the pyrethroid insecticide cypermethrin in soils. Pestic Sci 12(3):285-296

85. Girardi C, Greve J, Lamshoft M, Fetzer I, Miltner A, Schaffer A, Kastner M (2011) Biodegradation of ciprofloxacin in water and soil and its effects on the microbial communities. J Hazard Mater 198:22-30

86. Oi M (1999) Time-dependent sorption of imidacloprid in two different soils. J Agric Food Chem 47(1):327-332

87. Dalkmann P, Menke U, Schafer D, Keppler J, Patzold S (2012) Aging of methabenzthiazuron, imidacloprid, and N,N-dimethylsulfamide in silty soils and effects on sorption and dissipation. Environ Toxicol Chem 31(3):556-565

88. Lewandowska A, Walorczyk S (2010) Carbendazim residues in the soil and their bioavailability to plants in four successive harvests. Pol J Environ Stud 19(4):757-761

89. Lehr S, Scheunert I, Beese F (1996) Mineralization of free and cell-wallbound isoproturon in soils in relation to soil microbial parameters. Soil Biol Biochem 28(1):1-8

90. Cabrera A, Papiernik SK, Koskinen WC, Rice PJ (2012) Sorption and dissipation of aged metolachlor residues in eroded and rehabilitated soils. Pest Manag Sci 68(9):1272-1277

91. Haider K, Spiteller M, Dec J, Schäffer A (2000) Silylation of soil organic matter: extraction of humic compounds and soil bound residues. In: Bollag JM, Stotzky G (eds) Soil biochemistry, vol 10. Marcel Dekker, New York, pp 139-170

92. Madigan MT, Martinki J, Parker J (2011) Biology of microorganisms, international student edition, 13th edn. Pearson Inc., New York

93. Eschenbach A, Wienberg R, Mahro B (1998) Fate and stability of nonextractable residues of ${ }^{14} \mathrm{C}-\mathrm{PAH}$ in contaminated soils under environmental stress conditions. Environ Sci Technol 32(17):2585-2590

94. Weiss M, Geyer R, Gunther T, Kaestner M (2004) Fate and stability of ${ }^{14} \mathrm{C}$-labeled 2,4,6-trinitrotoluene in contaminated soil following microbial bioremediation processes. Environ Toxicol Chem 23(9):2049-2060

95. Weiss M, Geyer R, Russow R, Richnow HH, Kastner M (2004) Fate and metabolism of $\left[{ }^{15} \mathrm{~N}\right] 2,4,6$-trinitrotoluene in soil. Environ Toxicol Chem 23(8):1852-1860

96. Zhao Q, Li PJ, Stagnitti F, Ye J, Dong DB, Zhang YQ, Li P (2009) Effects of aging and freeze-thawing on extractability of pyrene in soil. Chemosphere 76(4):447-452

97. Zhao Q, Xing BS, Tai PD, Yang K, Li H, Zhang LZ, Lin G, Li PJ (2013) Effect of freeze-thawing cycles on aging behavior of phenanthrene, pyrene and their mixture in soil. Sci Total Environ 452:246-252

98. Eschenbach A (2013) Characterization of non extractable residues for their risk assessment in soil with special regards to pharmaceuticals. In: International workshop pharmaceuticals in soil, sludge and slurry, Dessau

99. Hanks DA, Webb BL, Jolley VDA (2007) Comparison of hot water extraction to standard extraction methods for nitrate, potassium, phosphorus, and sulfate in arid-zone soils. Commun Soil Sci Plant Anal. 28(15-16):1393-1402

100. Felsot AS, Dzantor EK (1995) Effect of alachlor concentration and an organic amendment on soil dehydrogenase-activity and pesticide degradation rate. Environ Toxicol Chem 14(1):23-28
101. Murillo-Zamora S, Castro-Gutierrez V, Masis-Mora M, Lizano-Fallas V, Rodriguez-Rodriguez CE (2017) Elimination of fungicides in biopurification systems: effect of fungal bioaugmentation on removal performance and microbial community structure. Chemosphere 186:625-634

102. Stella T, Covino S, Cvancarova M, Filipova A, Petruccioli M, D'Annibale A, Cajthaml T (2017) Bioremediation of long-term PCB-contaminated soil by white-rot fungi. J Hazard Mater 324:701-710

103. Wang Y, Zhang BW, Chen NJ, Wang C, Feng S, Xu H (2018) Combined bioremediation of soil co-contaminated with cadmium and endosulfan by Pleurotus eryngii and Coprinus comatus. I Soils Sediments 18(6):2136-2147

104. Loos M, Krauss M, Fenner K (2012) Pesticide nonextractable residue formation in soil: insights from inverse modeling of degradation time series. Environ Sci Technol 46(18):9830-9837

105. Brock AL, Kästner M, Trapp S (2017) Microbial growth yield estimates from thermodynamics and its importance for degradation of pesticides and formation of biogenic non-extractable residues. SAR and QSAR in Environ Res 28(8):629-650

106. Conant RT, Ryan MG, Agren Gl, Birge HE, Davidson EA, Eliasson PE, Evans SE, Frey SD, Giardina CP, Hopkins FM, Hyvonen R, Kirschbaum MUF, Lavallee JM, Leifeld J, Parton WJ, Steinweg JM, Wallenstein MD, Wetterstedt JAM, Bradford MA (2011) Temperature and soil organic matter decomposition rates - synthesis of current knowledge and a way forward. Glob Change Biol 17(11):3392-3404

107. Keiluweit M, Wanzek T, Kleber M, Nico P, Fendorf S (2017) Anaerobic microsites have an unaccounted role in soil carbon stabilization. Nat Commun 8:1771

108. Gulkowska A, Sander M, Hollender J, Krauss M (2013) Covalent binding of sulfamethazine to natural and synthetic humic acids: assessing laccase catalysis and covalent bond stability. Environ Sci Technol 47(13):6916-6924

109. Rein A, Adam IKU, Miltner A, Brumme K, Kastner M, Trapp S (2016) Impact of bacterial activity on turnover of insoluble hydrophobic substrates (phenanthrene and pyrene) —-model simulations for prediction of bioremediation success. J Hazard Mater 306:105-114

110. Jablonowski ND, Hamacher G, Martinazzo R, Langen U, Koppchen S, Hofmann D, Burauel P (2010) Metabolism and persistence of atrazine in several field soils with different atrazine application histories. J Agric Food Chem 58(24):12869-12877

111. Sniegowski K, Bers K, Ryckeboer J, Jaeken P, Spanoghe P, Springael D (2012) Minimal pesticide-primed soil inoculum density to secure maximum pesticide degradation efficiency in on-farm biopurification systems. Chemosphere 88(9):1114-1118

112. Krutz LJ, Shaner DL, Weaver MA, Webb RMT, Zablotowicz RM, Reddy KN, Huang YB, Thomson SJ (2010) Agronomic and environmental implications of enhanced s-triazine degradation. Pest Manag Sci 66(5):461-48

113. OECD_307 (2002) Aerobic and anaerobic transformation in soil. https ://www.oecd-ilibrary.org/docserver/9789264070509-en.pdf?expir es $=1543655258 \&$ id $=i d \& a c c n a m e=$ guest $\&$ checksum $=2582 \mathrm{ABEE} 7 \mathrm{C}$ 211E5BA095865571595959

114. OECD_308 (2002) Guideline for the testing of chemicals, No. 308 Aerobic and anaerobic transformation in aquatic sediment systems. https://www.oecd-ilibrary.org/docserver/9789264070523-en.pdf?expir es $=1543655324 \& \mathrm{id}=\mathrm{id} \&$ accname $=$ guest\&checksum $=47 \mathrm{~EB} 7 \mathrm{A6429}$ 809C00F429F4FCA9A01B8E. Accessed 1 Dec 2018

115. OECD_309 (2004) Guideline for the testing of chemicals, No. 309, Aerobic mineralisation in surface water-simulation biodegradation test. https://www.oecd-ilibrary.org/docserver/9789264070547-en.pdf?expir es $=1543655347 \& i d=i d \& a c c n a m e=$ guest\&checksum $=64$ B673DEEC 656500EA9BD7DBC3545663. Accessed 1 Dec 2018 